\title{
Effect of Annealing Temperature on Oxygen Reduction Reaction (ORR) Activity of Nitrogen and Sulfur Co-doped Mesoporous carbons
}

\author{
Qiaowei Tang ${ }^{1}$, Fang Dong ${ }^{1}$, Fengyuan Zhang ${ }^{2, *}$ and Jinli Qiao ${ }^{1, *}$ \\ ${ }^{1}$ College of Environmental Science and Engineering, Donghua Universtiy, 2999 Ren'min North \\ Road, Shanghai 201620, China \\ ${ }^{2}$ Nanodynamics and High Efficiency Lab for Propulsion \& Power, Department of Mechanical, \\ Aerospace \& Biomedical Engineering, University of Tennessee Space Institute, University of \\ Tennessee, Knoxville (UTK), United States
}

Corresponding author. qiaojl@dhu.edu.cn, fzhang@utsi.edu

Tel: +86-21-67792379. Fax: +86-21-67792159.

\begin{abstract}
Keywords: Annealing temperature, oxygen reduction reaction, $\mathrm{N}$ and $\mathrm{S}$ co-doped, mesoporous carbons

Abstract. In this work, we have synthesized N and S co-doped mesoporous carbons as highly efficient electrocatalysts to investigate the influence of annealing temperatures on electrocatalytic activity of $\mathrm{N}$ and $\mathrm{S}$ co-doped mesoporous carbon for oxygen reduction reaction (ORR) in alkaline media. The catalysts were prepared through silica hard template method, thermal annealing of ferrous chloride $\left(\mathrm{FeCl}_{2} 4 \mathrm{H}_{2} \mathrm{O}\right)$ and polyquaternium-46 (PQ) in nitrogen. Results of electrochemical characterizations for ORR were studied by cyclic voltammetry (CV) and linear sweep voltammetry (LSV) employing rotating disk electrode (RDE) technique. The peroxide yield $\left(\mathrm{H}_{2} \mathrm{O}_{2} \%\right.$ ) and electron transfer number (n) on the mesoporous carbon catalyzed electrode were investigated via the rotating ring-disk electrode (RRDE) experiments to study the ORR catalytic pathway of the catalysts. It is found that the temperature of the heat treatment is a significant parameter in synthesizing the high performance ORR catalysts. Of the three catalysts, $\mathrm{FeCl}_{2}-\mathrm{PQ}-800^{\circ} \mathrm{C}$ showed superior catalytic activity with onset potential at $0.965 \mathrm{~V}$ and half-wave potential at $0.807 \mathrm{~V}$. The corresponding electron transfer number was greater than 3.81, indicating that the ORR process proceeds mainly via a four-electron mechanism.
\end{abstract}

\section{Introduction}

Mesoporous carbon materials have been used for numerous applications such as adsorption [1], separation [2], supercapacitor [3] and oxygen reduction reaction (ORR) [4]due to their preeminent textural characteristics, high specific surface area, mechanical stability and porous structure. To date, extensive research efforts have been made to investigate the influence of experimental parameters on the catalytic activity of the ORR, such as the nitrogenated ligand in the precursor complex, chemical doping of mesoporous carbon, and duration of calcination [5]. Moreover, it has been demonstrated that temperature of annealing treatment plays an important role in the doping level of nitrogen and different binding configurations of the $\mathrm{N}$-doping, such as pyridinic-N, pyrrolic- $\mathrm{N}$ and graphitic- $\mathrm{N}$ [6]. Besides, it has been reported that the electrocatalytic activity of $\mathrm{N}$-doped graphene and S-doped graphene are both strongly dependant on the annealing temperature [7,8]. Herein, we report the $\mathrm{N}$ and $\mathrm{S}$ co-doped mesoporous carbon catalysts which was synthesisze via a green synthetic route with nanoscale $\mathrm{SiO}_{2}$ as the sacrificial template and polyquaternium-46 (Luviquat ${ }^{\mathrm{TM}}$ HOLD) as precursor of both nitrogen and sulfer source. After first-time graphitization, the silica was removed by excess amounts of $\mathrm{NaOH}$, and unreacted metallic iron and iron compounds were acid-leached before second-time annealing treatment. The two-step of the graphitization was carried out at different temperatures from 700 to $900^{\circ} \mathrm{C}$ to obtain the simultaneous optimization of both porous structures and surface functionalities of $\mathrm{N}$ and $\mathrm{S}$ co-doped carbon under $\mathrm{N}_{2}$ atmosphere. The electrocatalytic activities were studied by cyclic voltammetry (CV) and linear sweep voltammetry (LSV) employing rotatingring-disk electrode (RRDE). 


\section{Experimental}

Catalyst preparation. For the preparation of template $\mathrm{SiO}_{2}$ solution: silica of 500 nano-scale, as the starting materials, was mixed with hydrochloric acid solution $(1 \mathrm{M})$ and sonicated for 10 min, resulting in the homogeneous of binary $\mathrm{SiO}_{2}$ solution. Then $11.2 \mathrm{~g}$ polyquaternium-46 solution (20 wt. \%, Sigma-Aldrich) was added into the above $\mathrm{SiO}_{2}$ solution under magnetic stirring. A solution of $\mathrm{FeCl}_{2} 4 \mathrm{H}_{2} \mathrm{O}$ stirred for $5 \mathrm{~min}$ and further sonicated for $20 \mathrm{~min}$ was added into this mixture under stirring for more than $3 \mathrm{~h}$. The resulting viscous solution was dried at $85^{\circ} \mathrm{C}$ for $48 \mathrm{~h}$. The solid was ground to a fine powder in an agate mortar, and then pyrolyzed for $1 \mathrm{~h}$ at 700,800 and $900^{\circ} \mathrm{C}$ under a nitrogen atmosphere, with temperature ramp rate of $20^{\circ} \mathrm{C} \mathrm{min}{ }^{-1}$. The excess amount of sodium hydroxide $(\mathrm{NaOH})(4 \mathrm{M})$ was added to vacate the silica for $48 \mathrm{~h}$ and the resulting powder was washed by deionized water to neutralize it, and dried overnight. The final catalyst samples were obtained by exposure to acid-leaching using sulphuric acid $(0.5 \mathrm{M})$ at $85^{\circ} \mathrm{C}$ for $8 \mathrm{~h}$ to remove the unreacted metallic iron. After dried overnight, the resulting powder was re-pyrolyzed for $1 \mathrm{~h}$ at 700, 800 and $900^{\circ} \mathrm{C}$ under a nitrogen atmosphere, with temperature ramp rate of $20^{\circ} \mathrm{C} \mathrm{min}^{-1}$, respectively.

Electrochemical testing. For working electrode preparation, $2 \mathrm{mg} \mathrm{FeCl}_{2}-\mathrm{PQ}-\mathrm{T}(\mathrm{T}=700,800$, $900^{\circ} \mathrm{C}$ ) catalyst was dispersed in $400 \mu \mathrm{L}$ isopropyl alcohol (Sinopharm Chemical Reagent Co., Ltd). $100 \mu \mathrm{L} 0.5 \%$ Nafion (diluted with methanol) was added into the mixture to prepare the catalyst ink. Then the $12.4 \mu \mathrm{L}$ ink was applied onto a clean glassy carbon (GC) disk with a sectional area of 0.2475 $\mathrm{cm}^{2}$. The overall loading was $200 \mu \mathrm{g} \mathrm{cm}^{-2}$.

The electrochemical analysis was performed by CV, LSV, RDE and RRDE measurements on a $\mathrm{CHI}$ Electrochemical Station (Model 750b). The electrochemical experiment was carried out in a conventional three-electrodes cell, where $\mathrm{O}_{2}$-saturated $\mathrm{KOH}$ aqueous solution $(0.1 \mathrm{M})$ was used as electrolyte. GC disk was used as working electrode. A platinum wire and saturated calomel reference electrode (SCE) were used as counter electrode and reference electrode, respectively. All potentials were referred to reversible hydrogen electrode (RHE) in this work. The CV and LSV curves were obtained in the $\mathrm{O}_{2}$-saturated $\mathrm{KOH}(0.1 \mathrm{M})$ solution at the scanning rate of $50 \mathrm{mV} \mathrm{s}^{-1}$ and $5 \mathrm{mV} \mathrm{s}^{-1}$. The RRDE curves were measured with the scanning rate of $5 \mathrm{mV} \mathrm{s}^{-1}$ and working electrode rotation speed of $1600 \mathrm{rpm}$.

\section{Results and Discussion}

Cyclic voltammetry. As shown in Fig. 1, in the case of a $\mathrm{N}_{2}$-saturated solution, the cyclic voltammogram only presents a featureless voltammetric curve in the potential range of $0.5 \mathrm{~V}$ to 1.2 $\mathrm{V}$, which is ascribed to the typical double-layer capacitive current of porous carbon materials. When $\mathrm{O}_{2}$ was purged into the solution, a distinct cathodic current with the peak potential $\left(E_{\mathrm{p}}\right)$ at $0.78 \mathrm{~V}$ vs. RHE, and the peak current density $\left(I_{\mathrm{p}}\right)$ of $3.61 \mathrm{~mA} \mathrm{~cm}^{-2}$ can be clearly observed, indicating that this Fe-PQ- $800^{\circ} \mathrm{C}$ catalyst has a very high catalytic activity towards the ORR.

Linear sweep voltammetry. To further evaluate the electrocatalytic activity of $\mathrm{FeCl}_{2}-\mathrm{PQ}-\mathrm{T}(\mathrm{T}=$ 700,800 and $900^{\circ} \mathrm{C}$ ) for the ORR, LSV measurements were performed in $\mathrm{O}_{2}$-saturated $\mathrm{KOH}(0.1 \mathrm{M})$ solution by RDE technique. From the polarization curves showed in Fig. 2, it can be seen that the onset potential, half-wave potential and diffusion limit current density changed significantly by comparison of three different prepared catalysts. For $\mathrm{FeCl}_{2}-\mathrm{PQ}-800^{\circ} \mathrm{C}$, it showed a much better performance with onset potential ( $\left.E_{\text {onset }}\right)$ of $0.965 \mathrm{~V}$ and half-wave potential $\left(E_{1 / 2}\right)$ of $0.776 \mathrm{~V}$, which are $17 \mathrm{mV}$ and $6 \mathrm{mV}$ positive shifts more than that of $\mathrm{FeCl}_{2}-\mathrm{PQ}-700^{\circ} \mathrm{C}$, respectively. As for $\mathrm{FeCl}_{2}-\mathrm{PQ}-900^{\circ} \mathrm{C}$, the $E_{\text {onset }}$ and $E_{1 / 2}$ values were detected at $0.959 \mathrm{~V}$ and $0.818 \mathrm{~V}$, which are $11 \mathrm{mV}$ and $48 \mathrm{mV}$ positive shifts more than that of $\mathrm{FeCl}_{2}-\mathrm{PQ}-700^{\circ} \mathrm{C}$, respectively. In addition, $\mathrm{FeCl}_{2}-\mathrm{PQ}-800^{\circ} \mathrm{C}$ shows the limited current density of $6.6 \mathrm{~mA} \mathrm{~cm}{ }^{-2}$, which is enhanced greatly compared to $\mathrm{FeCl}_{2}-\mathrm{PQ}-900^{\circ} \mathrm{C}\left(5.7 \mathrm{~mA} \mathrm{~cm}{ }^{-2}\right)$, along with a better-defined diffusion-limiting current plateau. These results agreed with the previous discussions on grapheme oxides, demonstrating that porous nanosheets subjected to annealing under $\mathrm{NH}_{3}$ or $\mathrm{H}_{2} \mathrm{~S}$ atmosphere at different temperatures show different degree of reaction [7]. Thus, it is reasonable to refer that the resulted abundant functional groups such as carbonyl, carboxyl, lactone and quinone at the edges and in the plane were 
favorable for the binding of nitrogen and sulfur when annealed at $800^{\circ} \mathrm{C}$.

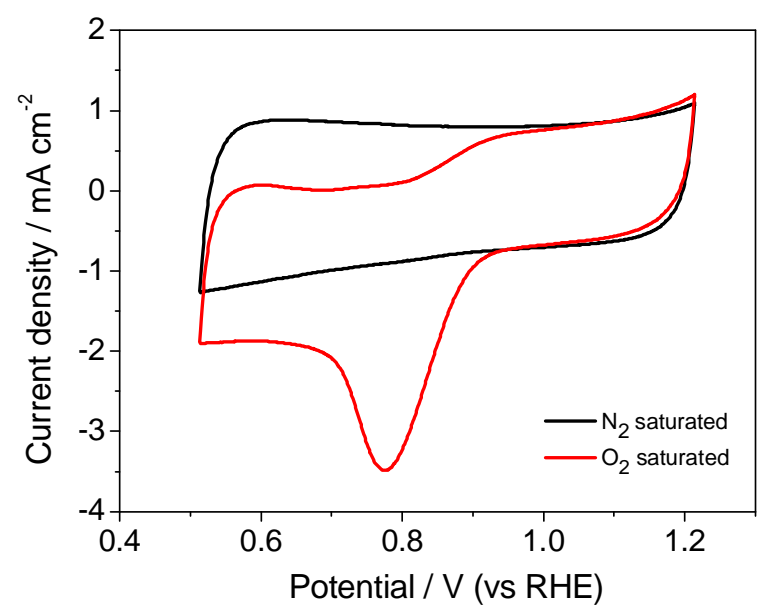

Fig. 1 Cyclic voltammograms of $\mathrm{FeCl}_{2}-\mathrm{PQ}-800^{\circ} \mathrm{C}$ in $\mathrm{N}_{2-}$ and $\mathrm{O}_{2}$-saturated $0.1 \mathrm{M} \mathrm{KOH}$; Scan rate: $50 \mathrm{mV} \mathrm{s}^{-1}$. The overall loading of the mixed catalyst: $200 \mu \mathrm{g} \mathrm{cm}^{-2}$.



Fig. 2 Polarization curves of $\mathrm{FeCl}_{2}-\mathrm{PQ}-\mathrm{T}$ ( $\mathrm{T}=700,800$ and $900^{\circ} \mathrm{C}$ ) in $\mathrm{O}_{2}$-saturated $0.1 \mathrm{M} \mathrm{KOH}$ solution. Potential scan rate: 5 $\mathrm{mV} \mathrm{s}^{-1}$. Electrode rotation rate: $1500 \mathrm{rpm}$.

RRDE measurements. RRDE measurements were performed to monitor the peroxide yield $\left(\mathrm{H}_{2} \mathrm{O}_{2} \%\right)$ and electron transfer number $(n)$ on the $\mathrm{FeCl}_{2}$-PQ-T $\left(\mathrm{T}=700,800\right.$ and $\left.900^{\circ} \mathrm{C}\right)$ catalyzed electrode to further study the ORR catalytic pathway of the catalyst. The $\mathrm{H}_{2} \mathrm{O}_{2} \%$ yield was determined based on the disk current $\left(I_{\mathrm{d}}\right)$ and ring current $\left(I_{\mathrm{r}}\right)$ via the following equation:

$$
\mathrm{H}_{2} \mathrm{O}_{2} \%=100 \times \frac{2 I_{r} / N}{I_{d}+I_{r} / N}
$$

The electron transfer number $(n)$ was thus obtained based on the following equation:

$$
n=\frac{4 I_{d}}{I_{d}+I_{r} / N}
$$

Where $\mathrm{N}=0.36$ is the current collection efficiency of the Pt ring, which was calibrated in $0.1 \mathrm{M}$ $\mathrm{KOH}$ with a10 $\mathrm{mM} \mathrm{K} \mathrm{K}_{3} \mathrm{Fe}(\mathrm{CN})_{6}$ electrolyte.

From Fig. 3(a), it can be found that the $\mathrm{H}_{2} \mathrm{O}_{2} \%$ yield was about $10 \%$ over the potential range of $0 \mathrm{~V}$ to $0.8 \mathrm{~V}$, while the $n$ was nearly 3.81 . Furthermore, the $\mathrm{H}_{2} \mathrm{O}_{2} \%$ yield was decreased generally with potential increasing, even there was little peroxide could be detected between $0.65 \mathrm{~V}$ to $0.8 \mathrm{~V}$. In brief, the whole tested potential range suggests that the $\mathrm{O}_{2}$ is mostly reduced to water rather than peroxide. As shown in Fig.3(b), on the $\mathrm{FeCl}_{2}-\mathrm{PQ}-800^{\circ} \mathrm{C}$, the $\mathrm{H}_{2} \mathrm{O}_{2} \%$ yield was detected to be less than $10 \%$ which is much lower than that of $\mathrm{FeCl}_{2}-\mathrm{PQ}-700^{\circ} \mathrm{C}$, implying a high $\mathrm{ORR}$ activity compared with $\mathrm{FeCl}_{2}-\mathrm{PQ}-700^{\circ} \mathrm{C}$. The electron transfer number of $\mathrm{FeCl}_{2}-\mathrm{PQ}-800^{\circ} \mathrm{C}$ was nearly 3.90 , which suggests that about $95 \% \mathrm{O}_{2}$ was reduced to $\mathrm{H}_{2} \mathrm{O}$ and other $\mathrm{O}_{2}$ was reduced to $\mathrm{H}_{2} \mathrm{O}_{2}$. For $\mathrm{FeCl}_{2}-\mathrm{PQ}-900{ }^{\circ} \mathrm{C}$, however, it showed the highest $\mathrm{H}_{2} \mathrm{O}_{2} \%$ yield and lowest electron transfer number among the three kinds of catalysts. The peroxide yield on $\mathrm{FeCl}_{2}-\mathrm{PQ}-900^{\circ} \mathrm{C}$ electrode was found nearly $11 \%$, and it sharply increased while the potential was above $0.8 \mathrm{~V}$. Meantime, the electron transfer number of $\mathrm{FeCl}_{2}-\mathrm{PQ}-900^{\circ} \mathrm{C}$ was about 3.80 , indicating that nearly $10 \% \mathrm{O}_{2}$ was reduced to $\mathrm{H}_{2} \mathrm{O}_{2}$ through $2 \mathrm{e}^{-}$ transfer process. The above results implying that when temperature is $700^{\circ} \mathrm{C}$ or $900^{\circ} \mathrm{C}$, it has low ORR activity result from fewer accessible active sites, compared with graphitization at $800^{\circ} \mathrm{C}$.

Further from Table 1 , the $\mathrm{FeCl}_{2}-\mathrm{PQ}-800^{\circ} \mathrm{C}$ gives the best onset potential, peak potential, peak current density, limited current density and electron transfer number compared to those of $\mathrm{FeCl}_{2}-\mathrm{PQ}-700^{\circ} \mathrm{C}$ and $\mathrm{FeCl}_{2}-\mathrm{PQ}-900^{\circ} \mathrm{C}$. This is probable due to more active sites and porous structure formed at $800^{\circ} \mathrm{C}$. All the experiments including the composition, morphology, and microstructure of 
the as-prepared $\mathrm{FeCl}_{2}-\mathrm{PQ}-\mathrm{T}$ catalysts characterized using XRD, EDS, XPS and nitrogen sorption analysis are in progress and the results will be reported in our further work.
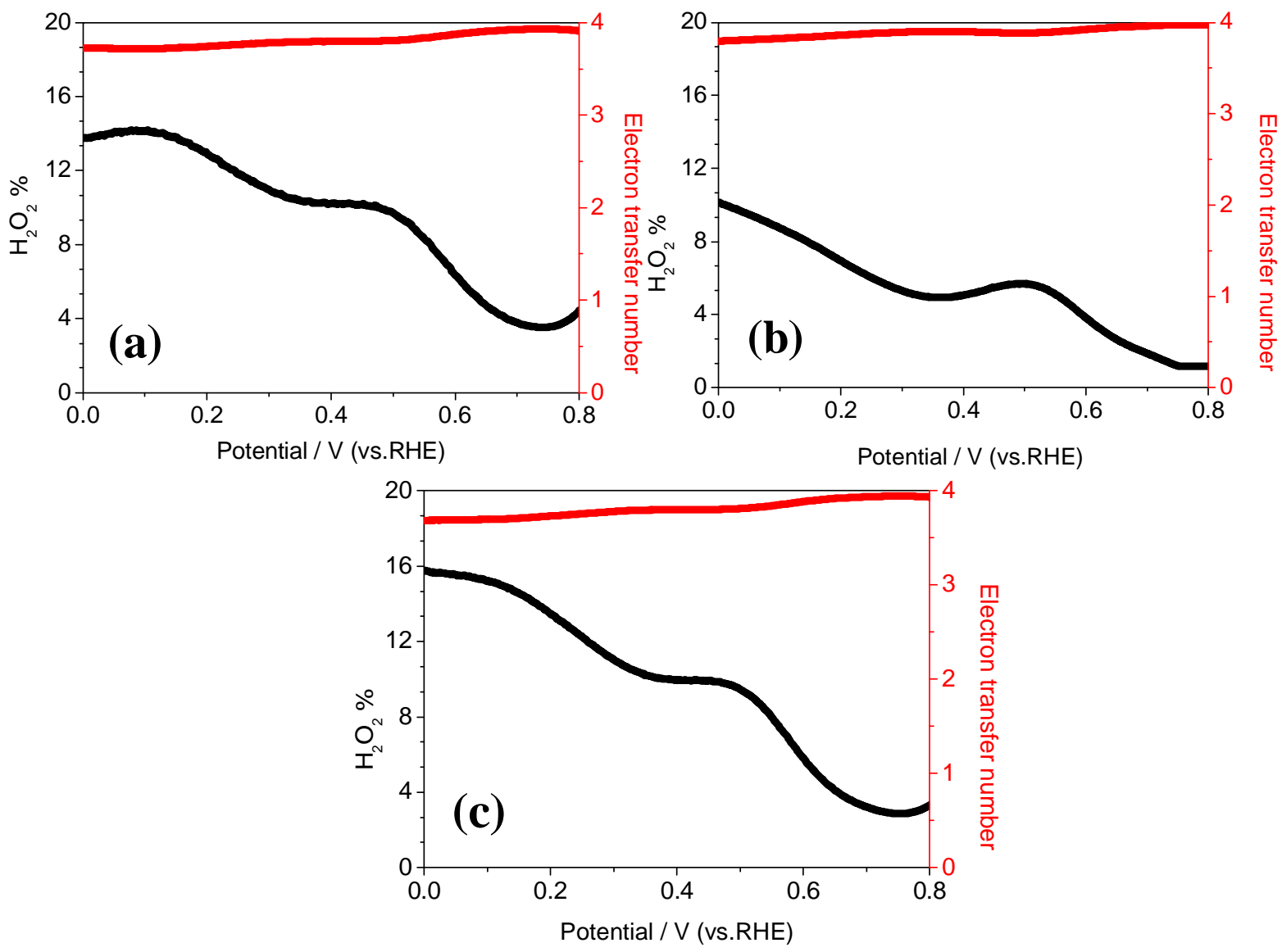

Fig. 3 Percentage of $\mathrm{H}_{2} \mathrm{O}_{2}$ produced and the electron transfer number of $\mathrm{FeCl}_{2}-\mathrm{PQ}-700^{\circ} \mathrm{C}$ (a), $\mathrm{FeCl}_{2}-\mathrm{PQ}-800^{\circ} \mathrm{C}$ (b) and $\mathrm{FeCl}_{2}-\mathrm{PQ}-900^{\circ} \mathrm{C}$ (c) with a rotation rate of $1600 \mathrm{rpm}$.

Table 1 Comparison of electrochemical data of $\mathrm{FeCl}_{2}-\mathrm{PQ}-\mathrm{T}\left(\mathrm{T}=700,800\right.$ and $\left.900^{\circ} \mathrm{C}\right)$

\begin{tabular}{rcccccc}
\hline Catalyst & $\begin{array}{c}E_{p} \\
(\mathrm{~V})\end{array}$ & $\begin{array}{c}I_{\mathrm{p}} \\
\left(\mathrm{mA} \mathrm{cm}^{-2}\right)\end{array}$ & $\begin{array}{c}i_{\mathrm{d}} \\
\left(\mathrm{mA} \mathrm{cm}^{-2}\right)\end{array}$ & $\begin{array}{c}E_{\text {onset }} \\
(\mathrm{V})\end{array}$ & $\begin{array}{c}E_{1 / 2} \\
(\mathrm{~V})\end{array}$ & $n$ \\
\hline $\mathrm{FeCl}_{2}-\mathrm{PQ}-700^{\circ} \mathrm{C}$ & 0.73 & 3.22 & 7.1 & 0.948 & 0.770 & 3.81 \\
$\mathrm{FeCl}_{2}$-PQ- $800^{\circ} \mathrm{C}$ & 0.78 & 3.61 & 6.6 & 0.965 & 0.807 & 3.90 \\
$\mathrm{FeCl}_{2}-\mathrm{PQ}-900^{\circ} \mathrm{C}$ & 0.76 & 2.74 & 5.7 & 0.959 & 0.818 & 3.80 \\
\hline
\end{tabular}

*the $i_{\mathrm{d},} E_{\text {onset }}$ and $E_{1 / 2}$ were measured at $1500 \mathrm{r} / \mathrm{min}$.

Morphology and structural characterization. The microstructures of the $\mathrm{FeCl}_{2}-\mathrm{PQ}-800^{\circ} \mathrm{C}$ was characterized by scanning electron microscopy (SEM) to explan its highest electrochemical properties for the oxygen reduction. Fig. 4(a) and (b) show the distribution of pores in the catalyst. We can clearly see a sponge-like structure with interconnected mesopores (2 50 nm)and macropores $(>50 \mathrm{~nm})$ system resulting from combined effect of the medi-template and metal salt. In terms of the results obtained from Fig. 4, the superior ORR performance of $\mathrm{FeCl}_{2}-\mathrm{PQ}-800^{\circ} \mathrm{C}$ may be closely related to its hierarchical porous structure.

\section{Conclusions}

The calcination temperatures play a critical role in synthetising the mesoporous carbon materials via hard template method for the oxygen reduction reaction. After annealing at different temperatures 

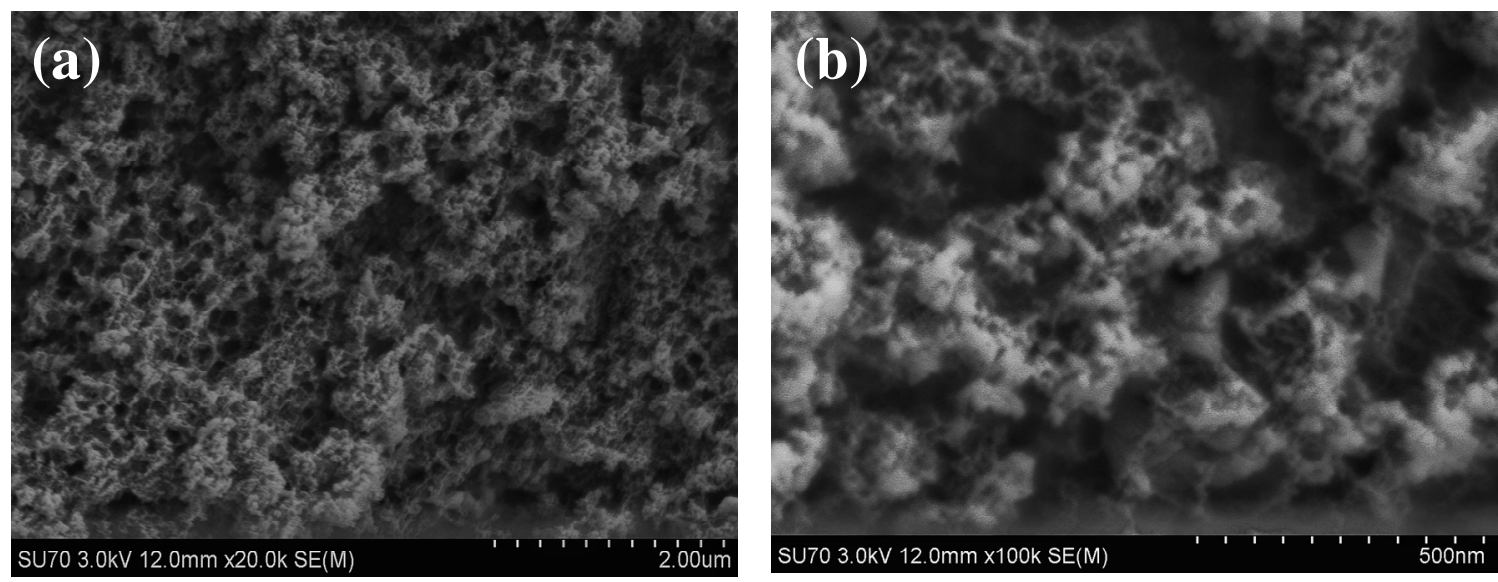

Fig. 4 SEM images of $\mathrm{FeCl}_{2}-\mathrm{PQ}-800^{\circ} \mathrm{C}$ catalyst, showing the highly porous structure. Scale bars: (a) $2.00 \mathrm{um}$ and (b) $500 \mathrm{~nm}$.

ranging from 700 to $900^{\circ} \mathrm{C}$, three distinct catalystswere obtained and investigated. Through the analysis of electrochemical characterization and distribution of porous, it can be concluded that the optimum heat-treatment temperature is $800^{\circ} \mathrm{C}$ and the $\mathrm{FeCl}_{2}-\mathrm{PQ}-800^{\circ} \mathrm{C}$ was the best performing catalyst, for which the onset potential at $0.965 \mathrm{~V}$ and half-wave potential at $0.807 \mathrm{~V}$ were obained, along with the ORR electron transfer number greater than 3.81 .

\section{Acknowledgements}

The authors acknowledge the financial support from the National Natural Science Foundation of China (U1510120), the International Academic Cooperation and Exchange Program of Shanghai Science and Technology Committee (14520721900), the Project of Introducing Overseas Intelligence High Education of China (2016-2017) and the College of Environmental Science and Engineering, State Environmental Protection Engineering Center for Pollution Treatment and Control in Textile Industry, Donghua University.

\section{References}

[1] A. Jain, R. Balasubramanian and M.P. Srinivasan: Chem. Eng. J. Vol. 273 (2015), p. 622-629.

[2] J.G. Zhou, Y.F. Wang, J.T. Wang, W.M. Qiao, D.H. Long and L.C. Ling: J. Colloid Interface Sci. Vol. 462 (2016), p. 200-207.

[3] W.Z. Chen, J.J. Shi, T.S. Zhu, Q. Wang, J.L. Qiao and J.J. Zhang: Electrochim. Acta. Vol. 177 (2015), p. 327-334.

[4] M.J. Wu, J.L. Qiao, K.X. Li, X.J. Zhou, Y.Y. Liu and J.J. Zhang: Green Chem. Vol. 18 (2016), p. 2699-2709.

[5] A. Serov, M.H. Robson, K. Artyushkova and P. Atanassov: Appl. Catal. B: Environ. Vol. 127 (2012), p. 300-306.

[6] X.F. Dai, J.L. Qiao, J.J. Shi, P.X., L. Zhang and J.J. Zhang: Int. J. Electrochem. Sci., Vol. 8 (2013), p. 3160-3175.

[7] X.J. Zhou, Z.Y. Bai, M.J. Wu, J.L. Qiao, Z.W. Chen: J. Mater. Chem. A, Vol. 3 (2015), p. 3343-3350.

[8] S. Tang, X.J. Zhou, N.N. Xu, Z.Y. Bai, J.L. Qiao and J.J. Zhang: Appl. Energy. Vol. 175 (2016), p. 405-413. 